\title{
Exploring Teacher Written Feedback and Student Revisions on ESL Students' Writing
}

\author{
Razlina Razali ${ }^{1}$, Rohaiza Jupri ${ }^{2}$ \\ ${ }^{1}$ Awang Had Salleh Graduate School of Arts and Sciences, Universiti Utara Malaysia \\ ${ }^{2}$ Department of Education and Modern Languages, Awang Had Salleh Graduate School of Arts and Sciences, \\ Universiti Utara Malaysia, Malaysia
}

\begin{abstract}
Realising the importance of writing in ESL classrooms, teachers are keen in devising various strategies that can help students to improve their writing skill. However, due to constraints, such as, time constraint and large number of students to attend to, teachers often find it difficult to provide feedback on students' written work. One of the ways that teachers can adopt in facilitating student revisions is through teacher written feedback. Past studies have shown that both teachers and students value teacher written feedback in the language classroom. This study investigates the effects of teacher written feedback on undergraduates' writing in an English L2 classroom at Universiti Malaysia Perlis, a local university in Malaysia. This study explores the use of three types of feedback- suggestion, criticism, and praise and which type of feedback from these three encourages student revisions. Mixed-method research design is used to obtain the data for this study. The success of revisions is discussed in terms of length and overall improvement in the revised compositions. This study reveals that all types of teacher written feedback encourage student revisions. In addition, findings also show that criticism type of feedback results in more successful revisions as it is more specific. The questionnaire also proves that students have positive attitude towards teacher written feedback.
\end{abstract}

Keywords: second language writing, student revisions, successful revisions, teacher written feedback, undergraduates

\section{Introduction}

The significance of teacher written feedback in the writing process is acquiesced by both teachers and students (Montgomery \& Baker, 2007). In second language (L2) writing, teacher written feedback plays an important part in coaching students the conventions of writing in a particular culture as well as L2 grammatical forms (Paulus, 1999). Zhang (1995) found that ESL students place greater appreciation and consistently rate teacher written feedback higher than other forms of feedback, such as peer feedback and oral feedback in writing conferences. Additionally, Ferris (1997) noted that teacher written feedback has resulted in text improvement where based on her research, it was found that the notes in the margin, requests for clarification and comments on grammar have led to students' revisions. However, due to time constraint and large number of students to attend to, especially in Malaysia where there are usually around 30 students in a class, teachers often face difficulty in giving adequate coaching to the students to improve themselves in their writing skill. In this mixed-method study, the effect of teacher written feedback on 28 English L2 undergraduates' revisions was investigated. For that purpose, qualitative data was collected through students' first and final essay drafts on the same topic. The qualitative data is important in addressing the purposes of this study, which are; to investigate which type of teacher written feedback that encourages student revisions and to find out what kind of changes influences the successful revisions. A questionnaire adapted from Silver and Lee (2007) was also used to see whether the teacher written feedback provided aligns with student preferences. As the role of teacher written feedback is undeniably important in improving students' writing especially in the L2 classroom, this study intends to address this topic.

\section{Research Questions}

1. What type of teacher written feedback encourages student revisions?

2. What kind of changes influences the successful revisions?

3. Does teacher feedback align with student preferences?

\subsection{Teacher Written Feedback}

\section{Literature Review}

Mack (2009) defines teacher written feedback as any comments, questions or error corrections that are written on students' assignments. These feedbacks can be given in many forms including questions, error corrections, praises and so on. According to Keh (1990), a review of literature has suggested that there are three 
types of feedback used as revision and they are: peer feedback, conferences as feedback, and teachers' comments as feedback. Hyland and Hyland (2006) see teacher written feedback as purely informational with its position as a medium for the teacher to channel responses and advices in assisting students' improvement. Teacher written feedback promotes students' revisions not only in L1 but also in the context of L2 when the feedback given is more specific, idea-based and meaning-level in multiple drafts (Paulus, 1999). In addition, teacher written feedback plays a significant role in providing a reader reaction to students' effort in writing, helping them to be better writers and to justify the grade given to the students (Hyland, 2003, cited in Hyland \& Hyland, 2006). For the purpose of this study, the effects of three types of integrated teacher written feedback; criticism, praise and suggestion (Hyland \& Hyland, 2001) on students' revision are investigated.

\subsection{Types of Teacher Written Feedback}

Based on Park's (2006) review on teacher written feedback in L2 writing, there are three types of teacher written feedback that are commonly used in L2 writing classrooms, which are: 1) form-focused feedback, 2) content-based feedback and 3) integrated feedback. The case of form-focused feedback or feedback on students' grammar has received much attention since Truscott (1996) argued that grammar correction in L2 classrooms should be abandoned. Citing previous studies of grammar correction in L1 and L2 classrooms, he concluded that grammar correction is ineffective. However, this claim is challenged by Ferris (2004). According to Ferris, more studies should be conducted in order to see whether feedback on errors is helpful or not. This is because as research in this particular area is scarce. The second type of feedback that is content or meaningbased feedback deals with the quality of the content and organizational features in students' composition. In this type of feedback, teachers will comment parts of the composition that do not make sense without pointing out specific grammatical errors (Park, 2006). In a study by Alamis (2010) in the Philippines, it was found that students have high preference for feedback in the area of content/organization compared to vocabulary and language use/grammar. The third type of written feedback is integrative feedback. This type of feedback results from the combination of grammar correction with content-related feedback (Park, 2006). In a study by Ashwell (2000), four cases of feedback; form feedback only, content-based feedback only, feedback combined with two types in a different order and two types of feedback simultaneously were studied. Findings from the study contradicted with Zamel's (1985) claim that content feedback should be given on earlier draft, followed by feedback on form on the following draft. Interestingly, the finding in his study also proved to contradict with Fathman and Whalley's (1990) and Ferris' (1997) notion that giving integrative feedback can be harmful. Studies in this area are still expanding and are being conducted thus, leading to new discoveries. However, reviews and new findings can provide new insights that can be useful for teachers to seek for the best method of feedback to suit their context of teaching.

\subsection{The Role of Teacher Written Feedback on Students' Writing Performance}

As proposed by psycholinguist Eric Lenneberg (1967), writing is similar to swimming in the sense that both are culturally specific, learned behaviour. Since writing is not a congenital ability, the role of teachers in facilitating students to be good writers is needed. The anticipated authoritative role of teachers has inspired research on the role of teacher as a responder to students' writing (Brown, 2001). This has also spearheaded various studies in the attempt to emphasize the role of teacher as a responder. The role of teacher as responder is achievable through teacher written feedback. Written feedback is an on-going process. This means it should happen continuously throughout the process of teaching and writing in achieving the final product (Ravichandran, 2002). What can be concluded from this is that teachers should provide feedback on students' drafts so that students will be able to make revisions and improvements in their writing. While there are other feedback providing strategies such as peer feedback, a study by Paulus (1999) on eleven ESL university students revealed that not only teacher feedback brought more influence in improving students' writing, it was also more favoured by the students as compared to peer feedback. Similarly, Hyland (2003) found that students highly regard form-focused feedback from teachers and they believed that this kind of feedback would be helpful in noting their errors so that improvements can be made.

Courses in universities often demand students to produce some kind of graded writing as a part of the course requirement. University students, likewise, regard their grades highly as it can be used to predict their overall grade at the end of the course. In order to address this issue, teacher written feedback can be used as one method to facilitate students to improve their grades. This is because as written feedback from the teacher highlights the most important aspects in students' writing that need to be improved. Through this, students would be able to make adjustments to improve their grades (Vardi, 2009). Albeit previous researchers such as Hillocks (1986), Knoblauch and Brannon (1981) who believed that written commentary on students' writing is generally ineffective, Silver and Lee (2007) confirmed in their study that teacher written feedback is crucial for ESL students' revision process as it helps to pinpoint their strengths and weaknesses. Other than helping in students' revision, teacher written feedback can also help students to be better motivated in writing. 
Ravichandran (2002) contends that students feel more motivated to engage in writing activities when teachers are more interested in their content rather than their language forms. Correspondingly, Ferris (2004) asserts that teacher's feedback on errors is much appreciated by students. "The lack of such feedback may lead to anxiety and resentment, which could decrease motivation and lower confidence in their teachers", (Ferris, 2004, p.56).

\subsection{Issues in Teacher Written Feedback and Pedagogical Implications}

Although in general, most previous studies have proven that teacher written feedback has brought positive changes in students' writing and also motivation, feedback alone is inadequate in helping students to improve. This may be due to the students' metacognitive knowledge inadequacy on the successful way to do revision based on the feedback given (Silver \& Lee, 2007). Thus, it is the teacher's task to make the students understand the feedback given to them so that students will be aware of the parts that need to be improved. In addition, Silver and Lee (2007) further maintained that low English proficiency and lack of appropriate strategies for providing explanations might not lead to successful revision by the students despite providing feedback. Result from a case study by Hyland (1998) concurs with this notion as it was found that one of the participants writing problem is related to the ineffective use of writing strategies and also low proficiency in English. Therefore, it is clear that improving students' writing performance should be beyond providing written feedback. Students need to incorporate their individualized strategies with the feedback provided by their teachers so that improvement in writing will occur (Paulus, 1999). Not only that, grammar instruction and also strategy training are also needed to help students improve in writing (Ferris, 2004).

Teachers should also be aware that the nature of their feedback also plays a role in the students' affective. A corrected draft with red ink all over the paper may not be a good way of providing feedback as it might give a negative effect on the students' apprehension level (Ravichandran, 2002). While praises are good in leveling up students' enthusiasm in writing, it did not encourage students to make revisions on their second draft (Silver \& Lee, 2007). Moreover, overly positive feedbacks also were found not to lead to any changes in students' drafts (Vardi, 2009). On the other hand, criticism as feedback leads to negative feelings from the students (Silver \& Lee, 2007). Lastly, teachers should try to communicate their written feedbacks with their students as this will promote effective improvements and revision. As suggested by Bitchener et al. (2005), students will be able to make improvements on their writing if they are exposed to oral and corrective feedback frequently. In addition, teachers should demonstrate the feedback to the students to raise their awareness about the aspects that need to be improved. This is maintained by Vardi (2009) that "global feedback was strongly related to change where it was augmented and supported by local feedback which modeled and made clear how and where the global feedback could be applied in the text" (p.355).

\subsection{Research Design and Participants}

\section{Methodology}

Mixed method was used by the researcher in this study, specifically, convergence parallel design. The rationale for choosing this kind of design is the data collected from both qualitative and quantitative can support each other and supply a more complete understanding of the research problems (Creswell, 2002). Data for this study mainly comes from students' compositions. The use of questionnaire is to support the qualitative data. In order to answer the three research questions of this study, collection of data was obtained through three sources: first drafts of students' compositions, the final drafts of the compositions and a student questionnaire adapted from Silver and Lee (2007). This study involves 28 students from three different classes, all approximately 19 to 27 years old, who were taking Foundation English course at Universiti Malaysia Perlis (UniMAP). These students came from different engineering disciplines such as mechanical engineering, electrical engineering, metallurgy engineering. All participants for this study were selected through purpose sampling. The reason why purpose sampling is chosen is that there is an equal opportunity of being chosen from the population. This is supported by Creswell (2008) that bias will be equally distributed among the people chosen for purpose sampling and the individuals that are chosen were the representative of the whole population. All students who participated in this study were Malaysians with a mix of Malays and Chinese except Indian race because there was just a small number of Indian students taking this course for this semester. The demographic profile collected showed that 24 of the students used their respective mother tongues to communicate at home, while another four of them used English and their mother tongues to communicate at home.

\subsection{Context of the Study}

This study took place within the context of an English remedial course, called Foundation English that runs for fourteen weeks at Universiti Malaysia Perlis (UniMAP), Perlis. This course is a compulsory course to be taken by bachelor's degree students who obtained Bands 1 to 3 in the Malaysian University English Test (MUET) (for Malaysian students), while all foreign students are required to sit for this course regardless of their proficiency level. This course is also aimed at raising the students' proficiency in English and it prepares them 
for the mainstream English Language Course - EUW 212 University English. In addition, this course covers the major aspects of grammar, reading, writing and speaking. However, grammar is taught incidentally. The teaching of writing for this course starts in week 9. At the time the research was conducted, there were altogether around 18 Foundation English classes at the university with six lecturers responsible in teaching this course. Each class of Foundation English consists around 20-30 students. However, not all students from each class were selected to be the participants of this study. Due to some constraints such as time limit and the reluctance of some lecturers to participate in this study, only ten students from three different classes were selected as participants of this study.

\subsection{Research Procedure}

Each student was required to write one piece of five-paragraph discussive essay on the topic, 'Ways to Prevent Air Pollution' that consisted of 300-350 words. The rationale for the lecturers giving this topic was because this was the students' first time writing a discussive essay. In addition, according to one of the lecturers, it is easier for the students to brainstorm ideas for this topic as it is something related to our daily life and the question is straight forward. The students were instructed to write the essay during a two-hour class time. When all the students in the three classes had completed their first draft of the essay, the researcher selected 10 pieces of essays randomly from each class. This step is important to avoid bias in selecting the participants because the researcher has no background knowledge about the language competency of the participants. Although initially the researcher selected 30 students for this study, only 28 first drafts and final drafts managed to be collected as two students were absent in the following week. Once the first drafts were collected, the researcher instructed the lecturers from the three classes to mark and give the written feedback to the drafts based on the three types of feedback suggested by Hyland and Hyland (2001) which are: praise, criticism and suggestion. In order to make the lecturers understand more about the types of feedback and their examples, the researcher provided the definitions of each feedback and their examples based on Silver and Lee (2007). Besides that, the researcher also conducted a short discussion with the lecturers involved to ensure the lecturers understand the process. The lecturers were informed to use at least one type of feedback type across all selected essays. However, they were free to use each type of feedback more than once for each essay.

After the lecturers had finished marking and providing feedback to the essays, the essays were returned back to the students during class time in the following week. The lecturers then instructed the students to rewrite the same essay during the two hours class time. Although Hattie and Timperly (2007), as cited in Mack (2009) suggest that giving feedback one week after the students have written the assignment is too late, it was unavoidable in this case as the students only meet their lecturers once a week. After the second drafts were completed, the first and second drafts were collected and compared to identify what type of feedback is widely used by lecturers and also which type of feedback encourages students' revisions. The student questionnaire that was used in this study was adapted from Silver and Lee (2007). The purpose of administering this questionnaire was to investigate the students' perception towards the writing in general and also their perception towards the lecturers' written feedback. The questionnaire consists four sections: 1) Section A is basically designed to gather background information of the students such as gender, age, programme, and ethnic group, 2) Section B consists 20 statements that are related to students' attitude towards writing in general, and also their attitude towards teacher written feedback. Each student was required to rate each statement based on a four-scale Likert scale ranging from 1 (strongly agree) to 4 (strongly disagree). 3) Section C consists two open-ended questions that require students to give their own opinions on which type of feedback that they like and dislike the most, and also their reasons for liking and disliking those types of feedback. The student questionnaire was given to the students after the composing and revising steps were completed. In order to make sure the students understood each statement and questions in the questionnaire, each statement was read out and explained by the lecturers before the students answered it. In addition, students were also told that their response will not have any effects on their marks whatsoever for the course and all responses were for research purposes only and would be treated as confidential.

\subsection{Data Analysis}

In attempting the answer for the first research question, the lecturers' written feedback on the first drafts of the essay was coded and classified into different categories of written feedback based on the definitions of suggestion, criticism and praise by Hyland and Hyland (2001) which acts as a model for this study to facilitate the coding process. The total number of teacher written feedback given was counted and the number of each feedback in the different categories was presented in the form of percentages. This method was easier as the researcher was able to identify which type of feedback was mostly used by the lecturers, and vice versa. In addition, by classifying the feedback given into three different categories, it enables the researcher to identify which type of feedback encourages student revision. Furthermore, the rationale for choosing this simple framework is, it is systematic and it can avoid "idiosyncratic" and "arbitrary" teacher responses (Sommers, 
1982), cited in Silver and Lee (2007). After each feedback on the first draft was identified and categorized based on the model, the first and the second drafts of the essays were compared to identify whether any revisions were made based on the feedback given on the first draft. To answer the second research question, each revision for each feedback type was coded and analyzed using the definitions of successful and unsuccessful revisions based on the definitions by Goldstein and Conrad (1999). Each revision made was categorized and analyzed based on the definitions to see whether they were successful or unsuccessful. The success of a revision is not judged based on the quantity of change, but, it is judged based on the quality of change. As defined by, Faigley and Witte (1981), "successful revision results not from the number of changes a writer makes but from the degree to which revision changes bring a text closer to fitting the demands of the situation" (p. 411). Thus, keeping this definition in mind, together with the definitions of successful and unsuccessful revisions by Goldstein and Conrad (1999) as guidelines, the total successful and unsuccessful revisions were totalled. In addition, in order to understand what kind of changes the successful revision leads to, the Taxonomy of Revision Changes by Faigley and Witte (1981) was used and each of the successful revisions based on the three feedback types was coded according to the taxonomy. In order to answer the third research question, a student questionnaire was distributed to the students after they had completed the composing and revising stages of the essay. The students' responses for each statement were tabulated using SPSS Version 17. This is important to see whether there is any relationship between students' attitude towards teacher written feedback and their revisions. In addition, students' responses in the questionnaire were cross-referenced with the findings in Research Question 1 and Research Question 2 to investigate whether teacher feedback aligns with student preferences.

\subsection{Reliability and Validity}

The use of the three types of commonly used written feedback by classroom teacher that are praise, criticism and suggestion helped to establish external and internal validity of this research (Silver \& Lee, 2007). In addition, method triangulation was also used to increase the validity of this research. This was achieved through collection of data from different sources such as collection of the students' first drafts and final drafts, and also collection of data through student questionnaire. In addition, validity was also achieved through external audit where the researcher selected three other English lecturers to help evaluate six randomly selected compositions (first drafts and final drafts) to check the coding which started from the classifications of the feedback, the success of the feedback and also the classifications based on the Taxonomy of Revisions. Furthermore, the use of the Taxonomy of Revisions also enhances the validity of the data analysis as this system is reliable with two previous researchers independently reached over $90 \%$ agreement on types of revisions (Faigley \& Witte, 1981). Additionally, as mentioned previously, the model for judging the types of revisions was constructed based on the definitions by Hyland and Hyland (2001). These three types of revisions are the most common types of feedback used in classroom and discussed in previous studies, thus, giving external and internal validity for this study. The reliability of the questionnaire is .416 . This suggests that this questionnaire has low internal consistency. This is due to the small sample size used in this study.

\section{Findings of the Study}

Overall, the findings showed that teacher written feedback on students' essays do lead to revisions on the final drafts. While some researchers like Hillocks (1986), Knoblauch and Brannon (1981) believed that teacher written commentary on students' compositions is normally not effective, this study proves that there were attempts made by students to revise based on the teacher written feedback. This is because when giving written feedback to the students, the teacher's role is no more seen as authoritarian but more to authoritative. The teacher will be the audience to the students' writing, thus helping students to understand the social and cultural contexts that they are performing in (Mack, 2009). This finding also concurs with previous studies, among them; Alamis (2010), Chandler (2003), and Ferris (1995), who purport that written feedback helps students in improving their writings. Therefore, this study proves the Sociocultural Theory by Lev Vygotsky (1986) that teacher written feedback acts as a tool for mediation. The teacher, as well as, the teacher written feedback, act as the means for students to develop their writing skills.

In addition, the findings showed that based on the three types of teacher written feedback used on the compositions, the type of feedback that led to student revisions was suggestions. This is also in line with the students' preference based on the questionnaire. The response from the questionnaire confirmed that students preferred suggestions compared to the other types of feedback. Thus, this study concurs with the results from Alamis (2010) and Silver and Lee (2007) where students from the studies also showed a high preference for suggestions. The students indicated that such feedback is important to help them in improving their writing and helped to improve their ideas. This can be seen as something positive in helping with their L2 development. Swain (1998), cited in Williams (2012) stated that writing helps L2 learners to notice holes. These holes can be filled by consulting experts, reference materials, or reflection on their existing knowledge. In this case, suggestions from the lecturers in the form of teacher written feedback can be used as one of the tools to help 
learners notice the holes. In addition, students tend to do more revisions based on suggestions because findings show that this type of feedback has the greatest quantity compared to the other two feedback types. This finding aligns with Vardi (2009) where students in the study appear to concentrate on areas that received most quantity of feedback.

Further analysis on the revisions revealed that most of the successful revisions were those that were given criticism type of feedback. This is related to the specificity of the feedback itself. Compared to suggestion, most of the feedback given in the form of criticism were specific. Although most revisions were made based on suggestion, they did not lead to most successful revisions as most of them were not specific. The criticism given pointed out the students' errors in a more straightforward manner. Among some of the examples of criticism given by the lecturers were: "You are still weak in your grammar", "incorrect use of preposition", "there is no thesis statement", and "there is no such word". Therefore, it is easier for students to revise as the lecturers specified what errors the students made. In contrast, it was found that lecturers used hedges for suggestion type of feedback. Words such as "please", "perhaps", "maybe" suggest that students are open for choices whether they want to make the changes or additions or not (Hyland \& Hyland, 2001).

The finding from this study corresponds with Keh (1990) where it was found that teacher written feedback that was short could cause problem as it did not provide enough information for the students to do revisions. In addition, Bitchener et al. (2005) also found that full, explicit written feedback improved the accuracy in later pieces of writing. Furthermore, this is supported by Ravichandran (2002) who claimed that teachers should attempt to create dialogues with the students as detailed and informative comments would allow teachers to reach out to the students better. Therefore, it can be concluded that most successful revisions are from criticism because majority of this type of feedback is specific, hence, leading to better understanding for the students to revise.

While most of the specific teacher written feedback led to revision, there were also cases where students did not make revisions even though specific feedback was provided. This brings to the second reason, which was the students' low level of proficiency. As stated previously, students who took this course were those who obtained Bands 1 to 3 in their MUET exam. This shows that the students' English proficiency level ranges from low to intermediate. This finding concurs with previous study by Silver and Lee (2007) where the lack of vocabulary in low to average English proficient students will be an obstruction for them to revise successfully. Moreover, previous studies also suggest that students might ignore or misuse teacher written feedback (Hyland \& Hyland, 2006). In addition, other problems such as misunderstanding the feedback given and sometimes, students understand the problems pointed out but they do not have the strategies to revise, are among the problems related to the success of a revision (Conrad and Goldstein; 1999; Ferris, 1997). Hence, students' English proficiency level also plays a role in determining the success of a revision.

Further analysis of the successful revisions using Taxonomy of Revisions by Faigley and Witte (1981) shows that most of the successful revisions are influenced by Surface Changes. This finding concurs with Faigley and Witte's (1981) study where it was found that inexperienced writers made Surface Changes the most. This finding somehow reflects the students' low proficiency level where changes in this area is regarded as less valuable as is it less likely to lead to better text (Hyland, 1998). In fact, Flower and Hayes also assert that novice writers almost always limit their revision to correcting errors (Faigley \& Witte, 1981), thus, this reasons out why most of the successful revisions were mostly made based on Surface Changes. In addition, Hyland (1998) further maintains that revisions that are valuable are the ones that change the meaning. This is because "the more revision focuses on meaning, the greater the potential for the development of the writer" (Hyland,1998, $\mathrm{p}$. 261). Additionally, Sommers (1980) asserts that, compared to inexperienced writers, skilled writers are more capable in changing whole chunks and focus on meaning in revisions.

According to Raimes (1985), unskilled ESL writers do not edit often because they are intimidated by the thought of error. This makes them more focused in the challenge of finding the correct words and sentences to convey their meaning in writing. Therefore, given that the students in this study were mostly low proficient students and inexperienced, most successful revisions that were made were only Surface Changes. From the findings, it was found that the preferred type of teacher written feedback between lecturers and students are aligned. This is because the types of teacher written feedback that are widely used by lecturers are mainly in the forms of (1) suggestion, followed by (2) criticism and lastly, (3) praise. On the other hand, responses from the questionnaire reveal that students highly prefer suggestion type of feedback and most of them dislike criticism. However, one student likes criticism as it can assist in improving writing and speaking skills. Silver and Lee (2007) also yielded the same results where their students showed high preference towards suggestion and disliked criticism. Furthermore, there was also one student who saw criticism as a tool in helping to improve writing skills.

In addition, finding from this current study also shows that students also like praise and this type of comment is usually associated with positive feelings. Alamis (2010) also found that students believed that feedback in the form of praise provided most help for them to improve in their writing. In contrast, a small 
number of students in this current study reasons out that praise could lead to detrimental effect on their written work where the positive comments will make them lazy to improve because of the feel-good factor. This also concurs with Hyland (1998) where one of the participants was against praise type of feedback as she claimed feedback given in the form of praise was insincere. Hyland (1998) further maintained that feedback in the form of praise gave a false impression to students about their real writing ability and eventually would lead them to distrust such feedbacks. Moreover, findings also suggest that students in general have a positive attitude towards writing compositions and teacher written feedback. This proves that students appreciate teacher written feedback on their written work. Previous studies among them are those by Cohen and Cavalcanti (1990), Hedgecock and Lefkowitz (1994), and Leki (1991), have found that students anticipate teacher comments for their errors and failure by the teacher in doing so will eventually lead to frustration (Hyland \& Hyland, 2006). Lastly, the findings also show that students desire feedback that are longer and more explicit. This, however, is not aligned with the teacher written feedback provided to them as most of the feedbacks given are not in specific manner. Findings from this study also show that specific feedback leads to revision even though it is given in the form of criticism. This affirms with previous studies, for instance, Zamel (1985) and Connors and Lunsford (1993), cited in Hyland and Hyland (2006) also claim that teachers' feedback on error is often incomplete, arbitrary and inaccurate and this problem often causes them to ignore or delete the errors to avoid the issues highlighted (Hyland, 1998). In short, it can be said that generally, teacher written feedback and student preferences are aligned. However, the explicitness of the teacher written feedback given by lecturers in this study does not satisfy the students' preferences.

\section{Conclusion}

The results from this study show that teacher written feedback holds an influence on student revisions. However, results also show that teacher written feedback does not necessarily lead to successful revisions. There are some reasons why teacher written feedback does not lead to successful revision and one of the problems lies in teacher written feedback itself. Teacher written feedback that is vague and too general could be confusing to the students, making it difficult for them to respond and incorporate the comments in their revision process, while too much criticism on errors could demotivate students to revise. Other than that, other factors such as students' inability to develop individualized strategies to incorporate teacher feedback in revisions (Paulus, 1999), and lack of English proficiency and lack of strategies to elaborate and explain their points (Silver \& Lee, 2007) also are the reasons why not all revisions are successful. However, despite all those problems concerning teacher written feedback and student revisions, from this study we found that students mostly value teacher written feedback on their compositions and there were attempts from students in making revisions based on teacher written feedback. In final consideration, the positive outcomes from this study show that it is undeniable that teacher written feedback encourages student revision, therefore, proving the Sociocultural Theory proposed by Lev Vygotsky. However, there is more that need to be done to help students fully utilize the feedback given to achieve better revisions. As recommended by Zamel (1985), teachers need to come out with better responses and correct their judgment of writing as a work in progress rather than as a finished product.

\section{References}

[1]. Alamis, M.M.P., (2010). Evaluating Students' Reactions and Responses to Teachers' Written Feedback. Philippine ESL Journal, 40-57.

[2]. Ashwell, T. (2000). Patterns of teacher response to student writing in a multiple-draft composition classroom: Is content feedback followed by form feedback the best method? Journal of Second Language Writing, 9(3), 227-

[3]. Bitchener, J. Young, S. \& Cameron, D. (2005). The Effect of Different Types of Corrective Feedback on ESL

257.

Student Writing. Journal of Second Language Writing, 191-205.

[4]. Chandler, J. (2003). The efficacy of various kinds of error feedback for improvement in the accuracy and fluency of L2 student writing. Journal of Second Language Writing. 267-296.

[5]. Creswell, J.W. (2002). Educational research: Planning, conducting, and evaluating quantitative and qualitative research, Boston:Pearson Education.

[6]. Creswell, J.W. (2008). Research design: Qualitative, quantitative, and mixed methods approaches: California: Sage Publications.

[7]. Faigley, L. \& Witte, S. (1981). Analysing Revision. College composition and communication, 400-414.

[8]. Fathman, A., \& Whalley, E. (1990). Teacher response to student writing: Focus on form versus content. In B. Kroll (Ed.) Second language writing: Research insights for the classroom (pp. 178-190). New York, NY: Cambridge University Press

[9]. Ferris, D. (1997). The influence of teacher commentary on student revision. TESOL Quarterly 31, 315-339

[10]. Ferris, D. R. (2004). The "Grammar Correction" Debate in L2 Writing: Where are we, and where do we go from here? (and what do we do in the meantime...?). Journal of Second Language Writing , 49-62.

[11]. Goldstein, L., \& Conrad, S. (1990). Student input and negotiation of meaning in ESL writing conferences. TESOL Quarterly, 24, 443-460.

[12]. Hyland, F. (1998). The Impact of Teacher Written Feedback on Individual Writers. Journal of Second Language Writing , 255286.

[13]. Hyland, K. \&. Hyland F. (2006). Feedback in Second Language Writing: Contexts and Sources. New York: Cambridge University Press. 
[14]. Hyland, F., \& Hyland, K. (2001). Sugaring the pill: Praise and criticism in written feedback. Journal of Second Language Writing, 10(3), 185-212.

[15]. Keh, C. L. (1990). Feedback in the writing process: a model and methods for implementation. ELT Journal , 294- 304.

[16]. Knoblauch, C., \& Brannon, L. (1981). Teacher commentary on student writing: The state of the art. Freshman English News, $10,1-4$.

[17]. Lantolf, J.P. (2000). Sociocultural Theory and Second Language Learning. Oxford: Oxford University Press.

[18]. Mack, L. (2009). Issues and Dilemmas: What conditions are necessary for effective teacher written feedback for ESL Learners? Polyglossia, 33-39.

[19]. Park, E. (2006). Review Article on "The Effectiveness of Teacher's Written Feedback on L2 Writing". Retrieved from: http://webcache.googleusercontent.com/search?q=cache:kC98w3t9Tw0J:sspace.snu.ac.kr/bitstream/10371/2051/1/workingpapers_v 5_61.pdf $+\& c d=1 \& h l=$ en\&ct $=$ clnk\&gl=my\&client=firefox $-\mathrm{a}$

[20]. Paulus, T. M. (1999). The Effect of Peer and Teacher Feedback on Student Writing. Journal of Second Language Writing , 265289.

[21]. Ravichandran, V. (2002). Responding to Student Writing: Motivate, Not Criticise. GEMA Online Journal of Studies.

[22]. Raimes, A. (1985). What unskilled ESL students do as they write: A classroom study of Composing. TESOL Quarterly. 229258.

[23]. Silver, R. \& Lee, S. (2007). What does it take to make a change? Teacher feedback and student revisions. English Teaching:Practice and Critique , 25-49.

[24]. Williams, J. (2012). The potential role(s) of writing is second language development. Journal of Second Language Writing, 321331.

[25]. Zamel, V. (1985). Responding to student writing. TESOL Quarterly, 19, 79-101. 